\title{
Development, characterization, in vitro and ex vivo evaluation of antiemetic transdermal patches of ondansetron hydrochloride and dexamethasone
}

\author{
Kailash Sahu ${ }^{1}$, Saman Pathan ${ }^{2,}{ }^{*}$, Kapil Khatri ${ }^{1}$, Neeraj Upmanyu ${ }^{3}$ and Satish Shilpi ${ }^{1}$ \\ ${ }^{1}$ Department of Pharmacy, Ravishankar College of Pharmacy, Bhopal (M.P.), India. \\ 2 Department of Pharmacology, All India Institute of Medical Science, Bhopal (M.P.) India. \\ ${ }^{3}$ Department of Pharmacy School of Pharmacy and Research people's university Bhopal (M.P.), India.
}

GSC Biological and Pharmaceutical Sciences, 2021, 14(03), 068-078

Publication history: Received on 02 February 2021; revised on 27 February 2021; accepted on 01 March 2021

Article DOI: https://doi.org/10.30574/gscbps.2021.14.3.0061

\begin{abstract}
The idea of delivering drugs through skin is old, as the use is reported back in $16^{\text {th }}$ century B.C. The husk of the castor oil plant in water was placed on an aching head. Today the transdermal drug delivery is well accepted for delivering drugs to the systemic circulation. The aim of this study was to design a compound transdermal patches containing ondansetrone HCL and dexamethasone for the treatment of nausea and vomiting in case of chemotherapy and regular symptom of nausea and vomiting. In the present work, an attempt has been made to develop a matrix-type transdermal therapeutic system comprising of Ondansetron- $\mathrm{HCl}$ and Dexamethasone in different ratios of hydrophilic and hydrophobic polymeric combinations with $15 \% \mathrm{w} / \mathrm{v}$ plasticizer and $5 \% \mathrm{w} / \mathrm{v}$ penetration enhancer were mixed with the polymer solution polymer were using solvent evaporation technique. The patches were further subjected to various characterization studies for prepared transdermal patches along with the thickness, tensile strength, folding endurance, $\%$ elongation, \% moisture content, \% moisture uptake, \% drug content, In vitro drug permeation study on Franz diffusion cells. Obtained results showed no physical-chemical incompatibility between drugs and polymers. On the basis

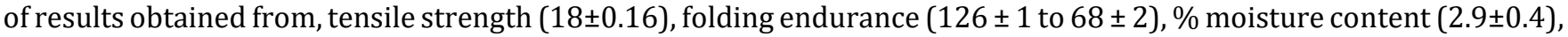
$\%$ moisture uptake, \% drug content (92.41 to 98.9\%), TPEC (Transdermal Patches of Ethyl Cellulose) was selected as optimized formulation. In vitro release of the selected batch, TPEC-1 followed by zero-order and formulation showed $62.69 \%$ drug diffusion within 10 hours. Conclusively, the patches were considered to deliver drugs safely through the skin for a longer period often.
\end{abstract}

Keywords: Transdermal drug delivery; Transdermal patches; Ondansetron HCl; Dexamethasone; Ex vivo etc.

\section{Introduction}

The concept and technology of controlled release have received increasing attention in the face of growing toxicity and ineffectiveness of drug when administration or applied by conventional method [1]. The findings accumulated over the years have practically revolutionized the old concept of impermeable skin barrier and motivated a number of pharmaceutical scientists to develop patch type drug delivery system for transdermal rate controlled administration of drugs for systemic medications. Transdermal drug delivery system can be defined as the delivery of drug across the epidermis to achieve systemic effects. The success of transdermal patches lies in their commercialization. Transdermal patches control the delivery of drugs at controlled rate by employing an appropriate combination of hydrophilic and lipophilic polymers [2-5].

Ondansetron is a serotonin (5-hydroxytryptamine) subtype 3 (5-HT3) receptor antagonist used in the management of nausea and vomiting [6-8]. 5-HT3 receptors, located centrally in the chemoreceptor trigger zone of the area postrema

\footnotetext{
* Corresponding author: Saman Pathan

Department of Pharmacology, All India Institute of Medical Science, Bhopal (M.P.) India.
} 
as well as peripherally on vagal nerve terminals, are key receptors in the nausea and vomiting response. Ondansetron has been used to prevent and control chemotherapy-induced nausea and vomiting (CINV), Ondansetron is also effective in controlling post-operative nausea and vomiting (PONV), radiotherapy and surgery [9].

Due to its short half-life and low bioavailability, it is administered orally 3 to 4 times a day, wherein the patient compliance is low [10]. Alternative route of drug administration like rectal and nasal administrations of ondansetron are also considered to have low patient compliance [11-12]. Drug in adhesive type transdermal delivery systems of ondansetron hydrochloride were developed by Gwak [13] but the flux achieved was significantly less than the desired flux. Hence, in the present study, an attempt has been made to assess the feasibility of ondansetron hydrochloride delivery through transdermal route using ethyl cellulose as release modulating polymeric system.

Dexamethasone is a synthetic glucocorticoid [14] widely used in inflammatory condition [15] and to enhance the normal immune response [16]. It is used as a therapeutic agent in alcohol withdrawal syndrome [17], cerebral edema [18], congenital adrenal hyperplasia [14], nausea, and vomiting, especially associated with a high dose of anticancer agents [19], high altitude disorder [18], cerebral malaria, opportunistic mycobacterial infections, respiratory disorders, skin disorders [14], and rheumatism [20]. Dexamethasone possesses most of the desirable physicochemical and biological properties, e.g. half-life of 2 and 5 hour, plasma protein binding is about $67 \%$, and a small daily dose ranging from 0.5 to $9 \mathrm{mg}$, while the associated drawbacks like hepatic first-pass effect of the drug and gastric irritation upon oral administration can also be overcome by transdermal delivery [21].

The goal of this work was to develop a matrix-type transdermal therapeutic system comprising of Ondansetron- $\mathrm{HCl}$ and dexamethasone in different ratios of hydrophilic and hydrophobic polymeric combinations such as penetration enhancer $(5 \% \mathrm{w} / \mathrm{v})$ was also incorporated in the formulation polyvinyl pyrolidoneoleic acid using solvent evaporation technique.

\section{Material and methods}

\subsection{Material}

Ondansetrone HCL powder was generous gift sample provided by Kopran Laboratories Ltd. Mumbai and Dexamethasone grade drug powder was gift sample provided by the Sun pharmaceutical industry Ltd. Mumbai. HPMC (Hydroxy-Propyl-methyl-cellulose) AR grade were purchased from Oxford Laboratories Limited Mumbai India. All other laboratory chemicals used in this study was analytical grade. Polyethylene glycol-400, Ethyl cellulose, polyvinyl pyrolidione K-30 (PVPK-30) was purchased from Oxford laboratory Mumbai India. Span-80 (AR grade) was purchased from Suvidhinath laboratories Baroda. Ethanol absolute obtained from Changshu Yangyuan chemical co. ltd China. All the liquid and powder material was stored at room temperature.

\subsection{Method}

\subsubsection{Formulation of Drug Loaded Transdermal Patches}

TDDS composed of different polymer combination $(10 \% \mathrm{w} / \mathrm{v})$ in different ratios of Ethyl cellulose and HPMC, HPMC and PVA, Ethyl cellulose and PVP containing Ondansatron- $\mathrm{HCl}$ and dexamethasone ( $\sim 1.2 \mathrm{mg} / \mathrm{square}$ centimeter patch) were prepared using the glass mould solvent evaporation technique [22]. Di-n-butyl phthalate was incorporated as a plasticizer at a concentration of $15 \% \mathrm{w} / \mathrm{w}$ of dry weight of polymers. Backing membrane was cast by pouring and then evaporating 5\% aqueous solution of polyvinyl alcohol in Petri dish covered on one side with aluminum foil, at $60^{\circ} \mathrm{C}$ for 6 hours. The matrix was prepared by pouring the homogeneous dispersion of drug with different blends of either type of lipophilic polymer (EC, HPMC or PVA) with PVP in chloroform on the backing membrane in Petri dish. The above dispersion was evaporated slowly at $40^{\circ} \mathrm{C}$ for 2 hour to achieve a drug-polymer matrix film then film was removed cut in $2 \mathrm{~cm}^{2}$ pieces and store in desiccators till further analysis or used (Figure 1). 


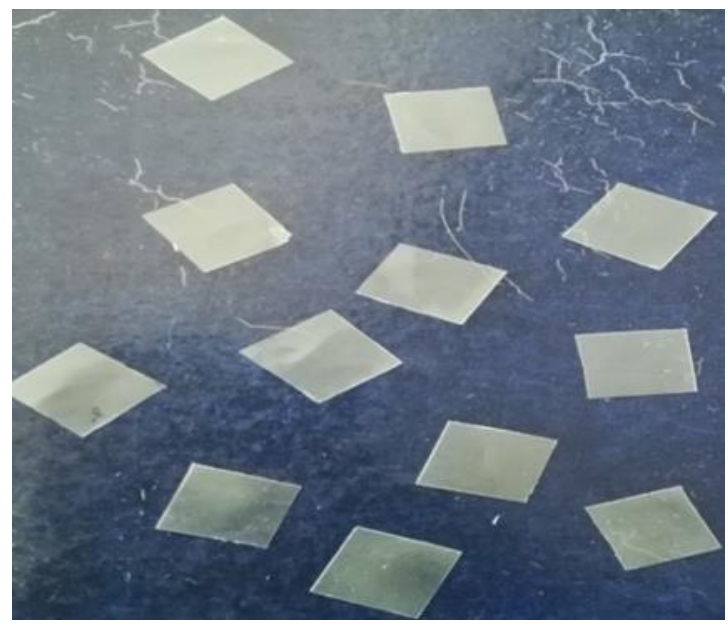

Figure $12 \times 2 \mathrm{~cm}^{2}$ Transdermal patch of TPEMC

\subsection{Characterization of Transdermal patches}

\subsubsection{Thickness}

The film thicknesses of prepared patches were measured by difference using Vernier calipers. The prepared patch was measured at five different points [23-24]. The thickness uniformity was measured at five different sites and average of five readings was taken with standard deviation (Table 2).

\subsubsection{Moisture content}

The prepared patches were cut into $20 \times 20 \mathrm{~mm}$ strips, were weighed individually and kept in a desiccator containing silica indicative type at room temperature for at least 24 hours or more until it showed a constant weight. The moisture content was the difference between the constant weight taken and the initial weight and was reported in terms of percentage (by weight) moisture content [25-26].

$\%$ Moisture content $=\frac{\text { Initial weight }- \text { finalweight }}{\text { Initialweight }} \times 100$

\subsubsection{Moisture uptake}

The water absorption capacities of various films were determined at $82 \%$ relative humidity (RH). Films were cut into $20 \times 20 \mathrm{~mm}$ strips, were weighed, kept in desiccators at room temperature for 24 hours, removed and exposed to RH conditions of $82 \%$ (containing saturated solution of potassium chloride) in different desiccators at room temperature. Weight was taken periodically until a constant weight was obtained. The water absorption capacity of the films (in weight \%) was calculated in terms of percentage increase in the weight of film over the initial weight of the strip [25, $27,28]$.

$\%$ Moisture absorption $=\frac{\text { Final weight-Initial weight }}{\text { Initial weight }} \times 100$

\subsubsection{Tensile Strength}

The tensile strength was determined by using a modified pulley system. It contains two clamps, one was fixed and other was movable. The strips of the patch $\left(2 \times 2 \mathrm{~cm}^{2}\right)$ was cut and set between these two clamps. Weight was gradually increased on the pan, so as to increase the pulling force till the patch broke. The force required to break the film was consider as a tensile strength and it was calculated as $\mathrm{kg} / \mathrm{cm}^{2}$. The thickness and width of strips were noted at three sites and average value was taken for calculation. The rate of change of stress was kept constant with the increment of $18,21,24,28,29,32,34,36 \mathrm{~kg} / \mathrm{cm}^{2}$ per 2 minutes [29-30].

The tensile strength was calculated by using following formula: Tensile Strength = (Break force/ axb)

Where, $a$ and $b$ are the width \& thickness, of the films respectively. 


\subsection{Folding endurance}

The disintegration apparatus was modified as a folding endurance apparatus. Folding endurances were measured to determine the ability of patch withstand to rupture. Folding endurance of films was determined by continually folding a small strip of film $(2 \mathrm{~cm} \times 2 \mathrm{~cm})$ at the same place till it broke. The number of time the film could be folded at the same place without breaking was the folding endurance value of that prepared transdermal film [31].

\subsection{Drug content}

To determine drug content the patch of area $2 \times 2 \mathrm{~cm}^{2}$ was cut into small pieces and dissolved in $100 \mathrm{ml}$ of isotonic phosphate buffer of $\mathrm{pH} 7.4$ and utrasonicated for $30 \mathrm{~min}$, then the solution were stirred with a magnetic bead continuously for 5 hours. After filtration, $1 \mathrm{ml}$ was withdrawn from the solution and diluted to $10 \mathrm{ml}$. The absorbance of the solution was taken at $310 \mathrm{~nm}$ for Ondansetron and $251 \mathrm{~nm}$ for Dexamethasone using concentration was calculated. By correcting dilution factor, the drug content was calculated [32-33].

\subsection{Weight variation}

The study was carried out on three films obtained from casting solution. The mean weight of the film as well as the deviation from the mean was obtained and the data was recorded. The weight of each patch was taken using electronic balance. The test was done to check the uniformity of weight and thus check the batch- to- batch variation [29, 34].

\subsection{In-vitro Drug Diffusion Study}

\subsubsection{Preparation of skin}

The In-vitro skin permeation of Ondansetron and dexamethasone from the selected TDDS through depilated rat abdominal skin was conducted using a modified Franz diffusion cell. The study was conducted in accordance with the Helsinki declaration and animal care and facilities in Principles and Methods of Toxicology.

Male Wistar rats weighing 180-200 gm were used and anesthetized with brief ether inhalation and killed by cervical dislocation. Their hair was removed with depilatory agent for 10 minutes about 12 hours before sacrifice and abdominal skin was carefully excised. The adhering fat and debris were carefully removed from the skin samples and kept in $-25^{\circ} \mathrm{C}$ deep freeze until used in the diffusion studies.

The skin samples were soaked in isotonic saline solution for 30 minutes before starting diffusion experiments. This procedure was carried out under approval of Ravishankar College of Pharmacy, Ethics Committee of Experimental Animals (1733/PO/Re/S/13/CPCSEA). When determining the number of animals, we have considered the reduction rule, and minimum number of rats has been used [22].

\subsection{Permeation study}

Normal saline containing 20\% v/v of polyethylene glycol 400 was used as bathing solution (Burger and Miller 1989) in the receptor compartment of a modified Franz diffusion cell. The selection of the receptor fluid is an important criterion in the In vitro skin permeation studies. Biphasic characteristics of the receptor fluid are desirable as the diffusion of drug molecules is through both aqueous and non-aqueous heterogeneous media. PEG 400 and normal saline are commonly chosen to provide the biphasic characteristics to the receptor fluid [36]. Moreover, PEG 400 is a noninteracting fluid for the receptor media [37].

The skin was mounted between donor and receiver compartments of the diffusion cell having capacity $300 \mathrm{ml}$ with the epidermis facing upward into the donor compartment. The film of area $2 \mathrm{~cm}^{2}$ to be tested was placed on the skin. The bathing solution in receiver compartment was agitated with a magnetic stirrer at a temperature of $34 \pm 1^{\circ} \mathrm{C}$ maintained thermostatically. Samples ( $1 \mathrm{ml}$ in each case) were withdrawn at regular intervals and fresh receptor fluid was added to maintain a constant volume of receptor fluid. The samples were analyzed spectrophotometrically at $310 \mathrm{~nm}$ for ondansetron and at $244 \mathrm{~nm}$ for dexamethasone, and the drug content was determined from the calibration curve. A similar set was run simultaneously using the patch (without drug) at the donor compartment as a skin patch control system to avoid the influence of inherent extracts from the skin or leaching of any material from the patch without drug on the absorbance at $310 \mathrm{~nm}$ and $249 \mathrm{~nm}$ for ondansetron and dexamethasone respectively, at which the sample aliquots were analyzed spectrophotometrically. The diffusion study was carried out for 72 hours and $1 \mathrm{ml}$ sample was withdrawn at interval of each suitable time $(0.5,1,2,4,6,8,12,24,48,72)$. The obtained data was use to determine the release kinetics of the formulations. 


\section{Results and discussion}

In the present study, efforts have been made to prepare ondansetron hydrochloride and dexamethasone transdermal patches using solvent evaporation technique. The films were prepared by using different hydrophilic polymers such as EC, HPMC, PVP and PVA.

Table 1 Formulation of Ondansetron $\mathrm{HCl}$ and Dexamethasone Patches

\begin{tabular}{|c|c|c|c|c|c|c|}
\hline \multirow[t]{2}{*}{ Formulation } & \multicolumn{3}{|l|}{ Polymer } & \multirow{2}{*}{$\begin{array}{l}\text { Plasticizer } \\
\text { PEG }(\% \mathrm{w} / \mathrm{w}) \\
\text { (gm) }\end{array}$} & \multirow{2}{*}{$\begin{array}{l}\text { Penetration } \\
\text { enhancer } \\
(\text { Span80) } \\
(\% w / w)\end{array}$} & \multirow{2}{*}{$\begin{array}{l}\text { Drug } \\
(\% w / w)\end{array}$} \\
\hline & $\begin{array}{l}\text { EC:HPMC } \\
10 \% \mathrm{w} / \mathrm{w}(\mathrm{g})\end{array}$ & $\begin{array}{l}\text { HPMC:PVA } \\
10 \% \mathrm{w} / \mathrm{w}(\mathrm{g})\end{array}$ & $\begin{array}{l}\text { EC:PVP } \\
10 \% w / w(g)\end{array}$ & & & \\
\hline TPEMC - 1 & $1: 1$ & - & - & $1.5 \%$ & $5 \%$ & $10 \%$ \\
\hline TPEMC - 2 & $1: 2$ & - & - & $1.5 \%$ & $5 \%$ & $10 \%$ \\
\hline TPEMC -3 & $1: 3$ & - & - & $1.5 \%$ & $5 \%$ & $10 \%$ \\
\hline TPVAMC -1 & - & $2: 8$ & - & $1.5 \%$ & $5 \%$ & $10 \%$ \\
\hline TPVAMC -2 & - & $5: 5$ & - & $1.5 \%$ & $5 \%$ & $10 \%$ \\
\hline TPVAMC -3 & - & $8: 2$ & - & $1.5 \%$ & $5 \%$ & $10 \%$ \\
\hline TPEVP -1 & - & - & $8: 2$ & $1.5 \%$ & $5 \%$ & $10 \%$ \\
\hline TPEVP -2 & - & - & $5: 5$ & $1.5 \%$ & $5 \%$ & $10 \%$ \\
\hline TPEVP -3 & - & - & $2: 8$ & $1.5 \%$ & $5 \%$ & $10 \%$ \\
\hline
\end{tabular}

\subsection{Physio-chemical Evaluation}

\subsubsection{Thickness and Folding endurance}

The thickness of the TPEMC films varied from 0.4 to $0.8 \mathrm{~mm}$. The maximum standard deviation assured that the process used for preparing the delivery system is capable of giving reproducible results. This fact further confirmed by drug content and weight uniformity studies. In order to evaluate the flexibility, the films were subjected to folding endurance studies. The values in the range of 68 to 126 were observed in all batches. This revealed that the prepared films were having capability to withstand the mechanical pressure along with good flexibility (Table 2 and Figure 1 and 7).

Table 2 Physical Characterization of Transdermal Patches.

\begin{tabular}{|c|c|c|c|c|c|c|c|}
\hline $\begin{array}{l}\text { Formulation } \\
\text { code }\end{array}$ & $\begin{array}{l}\text { Thickness } \\
\text { index } \\
(\mathrm{mm})\end{array}$ & $\begin{array}{l}\text { Moisture } \\
\text { content } \\
(\%)\end{array}$ & $\begin{array}{l}\text { Moisture } \\
\text { uptake } \\
(\%) \\
\end{array}$ & $\begin{array}{l}\text { Tensile } \\
\text { strength } \\
\left(\mathrm{kg} / \mathrm{cm}^{2}\right)\end{array}$ & $\begin{array}{l}\text { Folding } \\
\text { endurance } \\
\text { (Times) }\end{array}$ & $\begin{array}{l}\text { Drug } \\
\text { content in } \\
\text { (ml) }\end{array}$ & $\begin{array}{l}\text { Weight } \\
\text { variation } \\
\text { (g) }\end{array}$ \\
\hline TPEMC - 1 & $0.59 \pm 0.14$ & $2.5 \pm 0.23$ & $4.7 \pm 0.15$ & $18 \pm 0.16$ & $68 \pm 0.26$ & $92.23 \pm 0.12$ & $0.482 \pm 0.21$ \\
\hline TPEMC - 2 & $0.53 \pm 0.13$ & $2.9 \pm 0.35$ & $5 \pm 0.14$ & $21 \pm 0.26$ & $73 \pm 0.35$ & $92.36 \pm 0.11$ & $0.521 \pm 0.12$ \\
\hline TPEMC -3 & $0.45 \pm 0.32$ & $3.3 \pm 0.13$ & $5.4 \pm 0.11$ & $29 \pm 0.23$ & $89 \pm 0.12$ & $92.53 \pm 0.16$ & $0.965 \pm 0.11$ \\
\hline TPVAMC -1 & $0.48 \pm 0.65$ & $4.2 \pm 0.5$ & $6.2 \pm 0.12$ & $32 \pm 0.25$ & $126 \pm 0.2$ & $97.61 \pm 0.15$ & $1.85 \pm 0.36$ \\
\hline TPVAMC - 2 & $0.61 \pm 0.45$ & $3.9 \pm 0.16$ & $5.9 \pm 0.32$ & $28 \pm 0.20$ & $95 \pm 0.12$ & $97.63 \pm 0.20$ & $1.35 \pm 0.5$ \\
\hline TPVAMC -3 & $0.85 \pm 0.32$ & $3.5 \pm 0.6$ & $4.5 \pm 0.6$ & $22 \pm 0.21$ & $82 \pm 0.86$ & $97.71 \pm 0.22$ & $2.21 \pm 0.14$ \\
\hline TPEVP -1 & $0.82 \pm 0.12$ & $1.8 \pm 0.12$ & $1.3 \pm 0.35$ & $15 \pm 0.23$ & $71 \pm 0.75$ & $98.45 \pm 0.35$ & $2.25 \pm 0.14$ \\
\hline TPEVP -2 & $0.71 \pm 0.21$ & $2.3 \pm 0.13$ & $1.5 \pm 0.22$ & $24 \pm 0.30$ & $83 \pm 0.15$ & $98.62 \pm 0.32$ & $1.45 \pm 0.19$ \\
\hline TPEVP -3 & $0.65 \pm 0.31$ & $2.8 \pm 0.12$ & $2.3 \pm 0.25$ & $28 \pm 0.31$ & $92 \pm 0.31$ & $98.84 \pm 0.42$ & $1.95 \pm 0.15$ \\
\hline
\end{tabular}




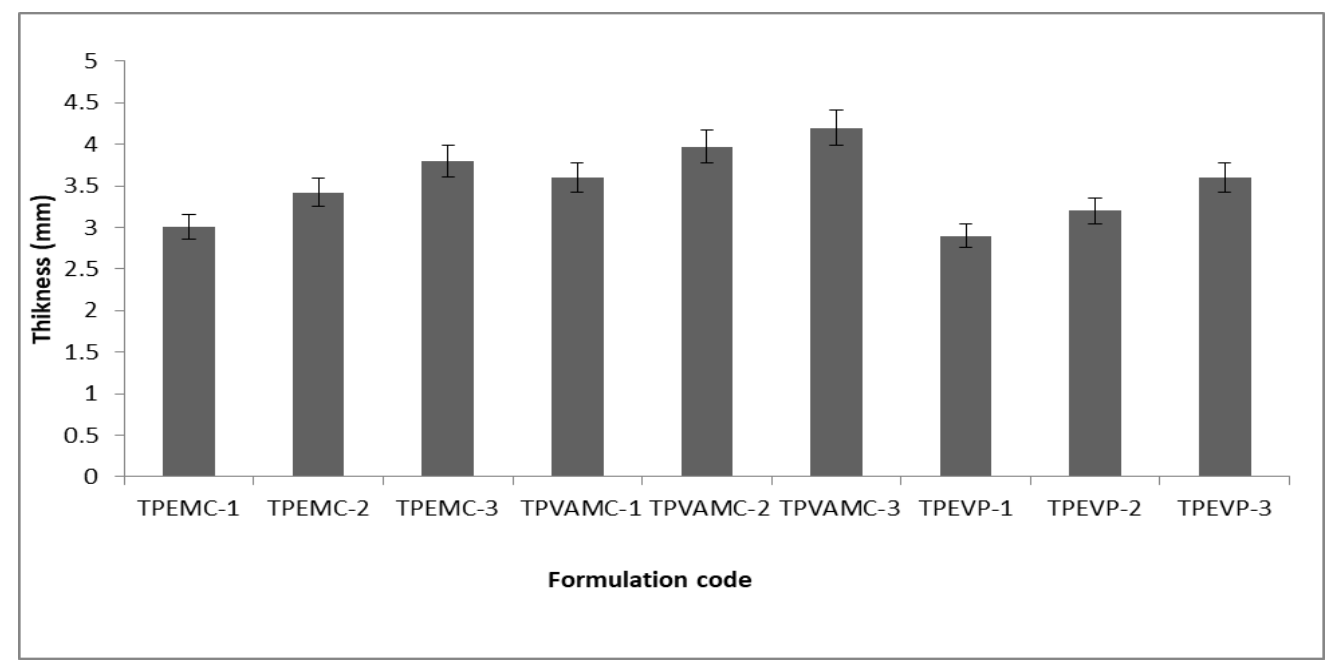

Figure 1 Thickness of patches of different formulations

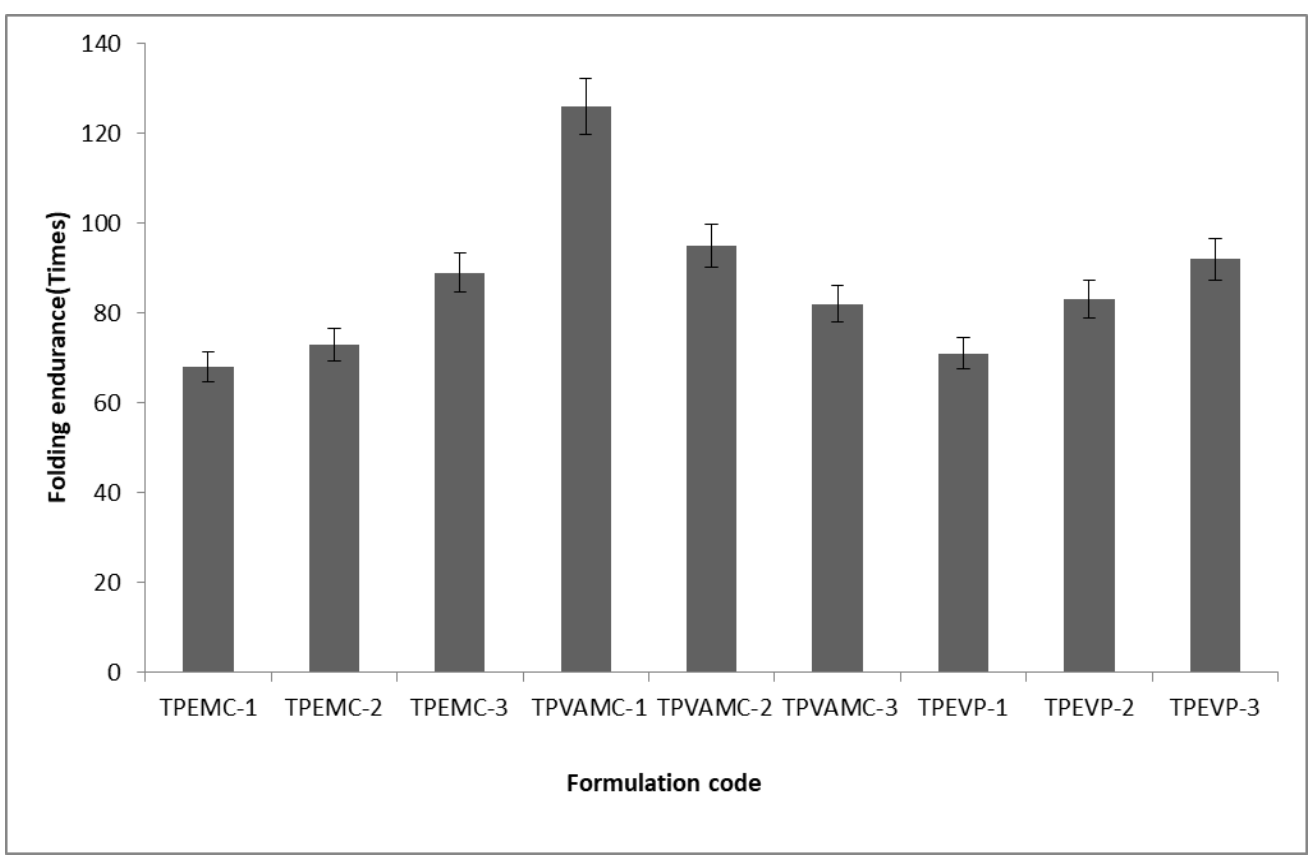

Figure $2 \%$ Folding Endurance of patches

\subsection{Moisture uptake}

The physio-chemical evaluation data of table 2 and Figure 2 indicates that the formulation TPVAMC-1 (HPMC $0.7 \%$ and PVA 2.8\%) has shown the highest maximum absorption (6.2 \pm 0.12$)$ than the other formulation. This may be due to the presence of high hydrophilicity of HPMC and PVP. The batch TPEVP-1 (EC 2.8\% and PVP 0.7\%) has shown the least percent moisture absorption. This might be due to the presence of the polymers in unequal composition hindered the moisture absorption characteristics. Moisture in optimum value helps to maintain the flexibility of patches. Patches contain very small amount of Moisture may be brittle in nature. The formulation show patches that were formulate with water soluble polymer show high moisture due to their water absorption capacity.

\subsection{Moisture content}

The batch TPVAMC-1 (HPMC 0.7\% and PVA 2.8\%) has shown the thigh moisture loss (4.2 \pm 0.5 ) when compared to batch TPEVP-1 (EC 2.8\% and PVP 0.7\%), (1.8 \pm 0.12$)$. This could be attributed to the low moisture retaining capacity of the ethyl cellulose and PVP (Table 2 and Figure 3). 


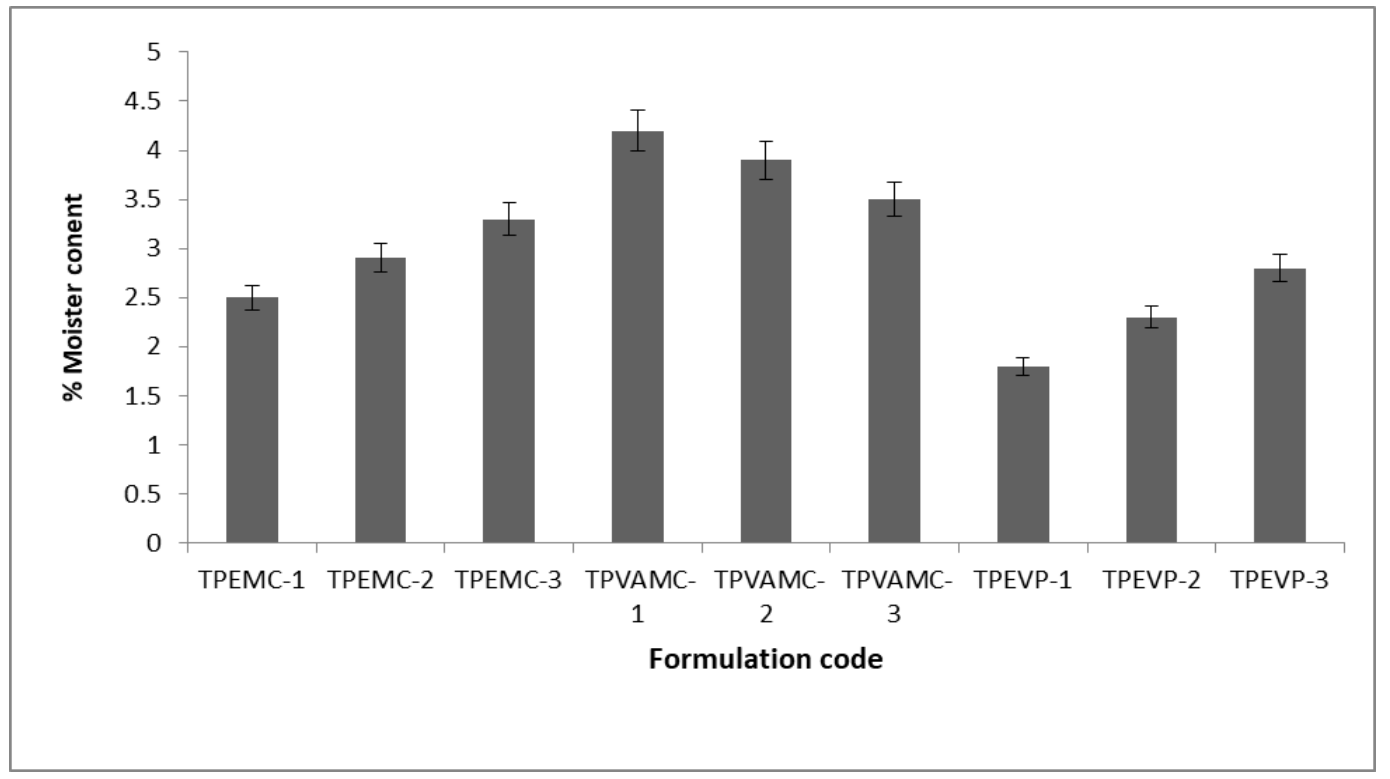

Figure $3 \%$ Moisture content of patches

\subsection{Tensile strength}

Tensile strength mainly depends upon the concentration of plasticizer used in the formulation. The tensile strength was found to be in the range of $15 \mathrm{~kg} / \mathrm{cm}^{2}$ to $32 \mathrm{~kg} / \mathrm{cm}^{2}$ to. Low tensile strength of patches was easily breakable and high strength makes patch brittle. Tensile strength of patches was also depends on polymer concentration or ratio of polymer and plasticizer. The batch TPVAMC- 1 showed the highest tensile strength i.e. $32 \pm 0.25$ and the batch TPEVP- 1 shown the lowest tensile strength i.e. $15 \pm 0.23$ (Table 2 and Figure 4).

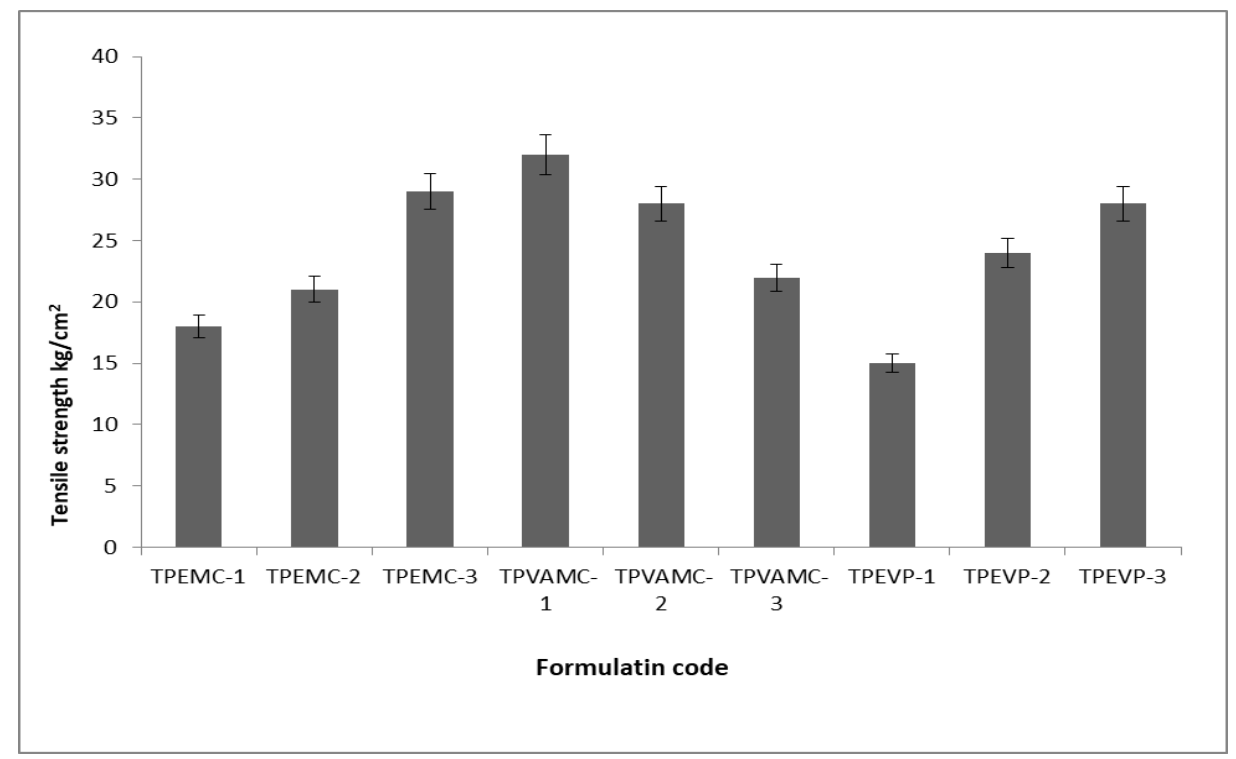

Figure $4 \%$ Tensile strength of Patches

\subsection{Weight variation}

The weight variation of patches was found in the range of 0.48 to 2.25 . The assessment of weight variation was performed by weighing individually drug loaded five patches of every formulation on a digital balance. The average weights were calculated and the standard deviation from the average weights measured, which revealed that thickness were increases as hydrophilic portion of polymer increases. Weight variation of patches was also depends on polymer concentration or ratio of polymer and plasticizer. (Table 2 and Figure 5). 


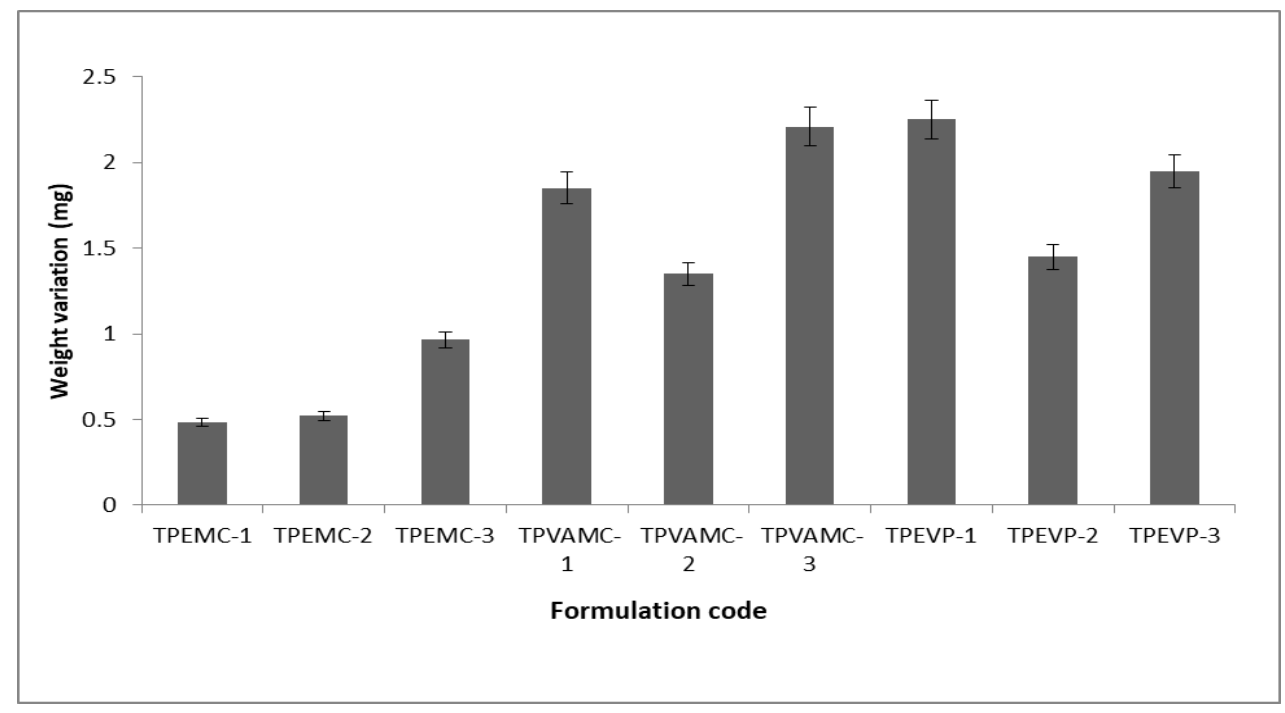

Figure 5 Weight variation of Patches

\subsection{Drug content}

The drug content was in the range of 92 to 98 . \% for all the formulations, suggested that the drug and polymers uniformly distributed in matrix dispersion. It also suggested that method of preparation was suitable for the formulation of transdermal matrix patch of ondansetron hydrochloride or Dexamethasone (Table 2 and Figure 6).

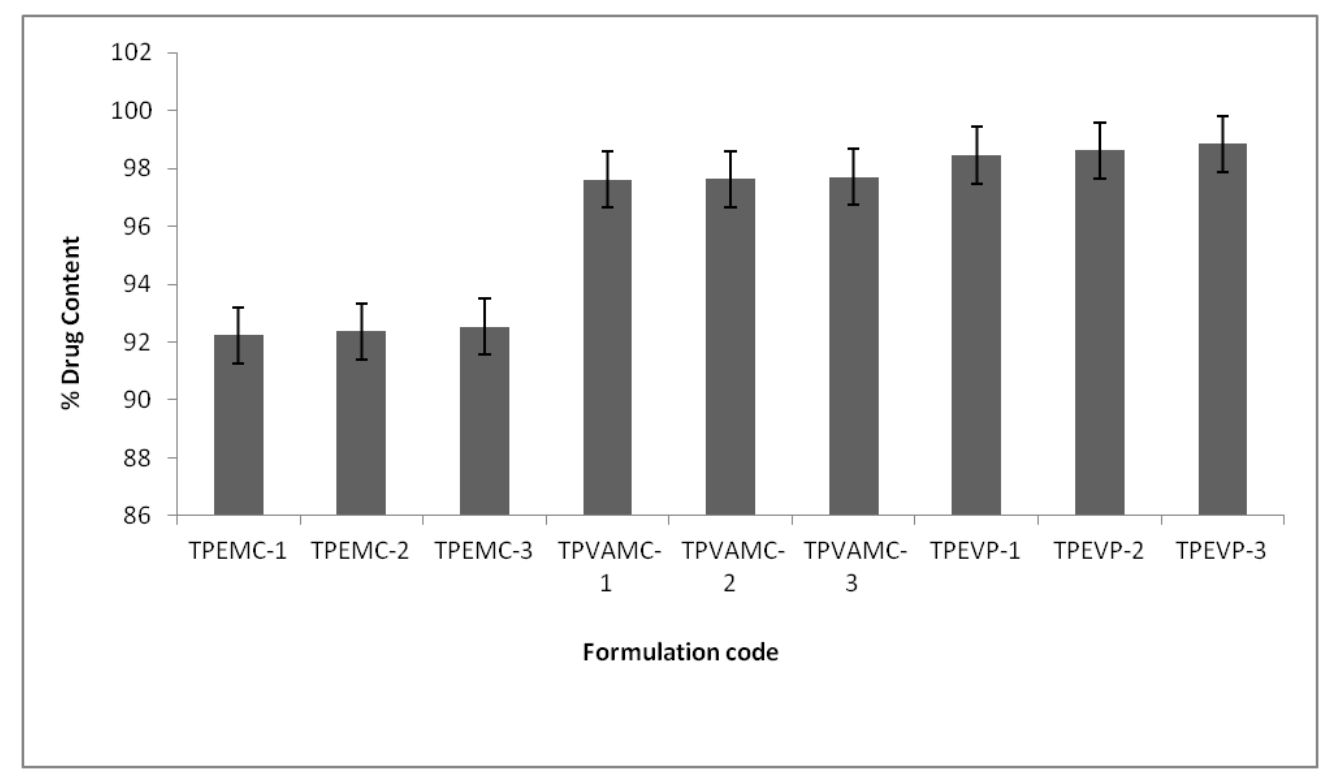

Figure $6 \%$ Drug content of patches

\subsection{In vitro and In vivo Drug Diffusion Study}

The rat skin was used to carry out the study. The formulation TPEMC (EC: HPMC-1:1) showed drug diffusion for 10 hours up to $62.69 \%$. The $\%$ drug diffusion from all the prepared formulations is given in the table-1.The drug release for different formulations i.e. TPEMC-1, TPEMC-2, TPEMC-3, TPVAMC-1, TPVAMC-2, TPVAMC-3, TPEVP-1, TPEVP-2, TPEVP-3 was found $52.11 \pm 31,54.09 \pm 36,55.01 \pm 0.16,56.01 \pm 32,59.09 \pm 0.22,62.09 \pm 35,65.095 \pm 32,68.099 \pm 01$ in 48 hours respectively. In ex-vivo drug release data of final selected optimized batch was subjected to different kinetic models to study the mechanism of drug release and found the regression coefficient $\left(\mathrm{R}^{2}\right)$ for Zero order was 0.9776 , for first order 0.5335, for Matrix Diffusion Higuchi was 0.9933 , which indicated that diffusion might be one of the prominent mechanism influencing the drug release, for Korsmeyer-Peppas was 0.9487, and for Hixson Crowell it was found 0.6726. Regression coefficient also suggested that drug release from the patch follow zero order and from the patch drug was release continuously in a controlled manner up to 24 hours. The correlation coefficient $\left(\mathrm{R}^{2}\right)$ of Higuchi's model was 
found to be 0.9933 that indicates diffusion of drug from the prepared patches. Thus, the selected batch TPEMC 1 followed zero order. Drug release mechanism occur first by swelling of polymer matrix and then drug was diffuse out from the matrix, so it follows Higuchi's and Korsmeyer- Peppas model more effectively (Figure 7).

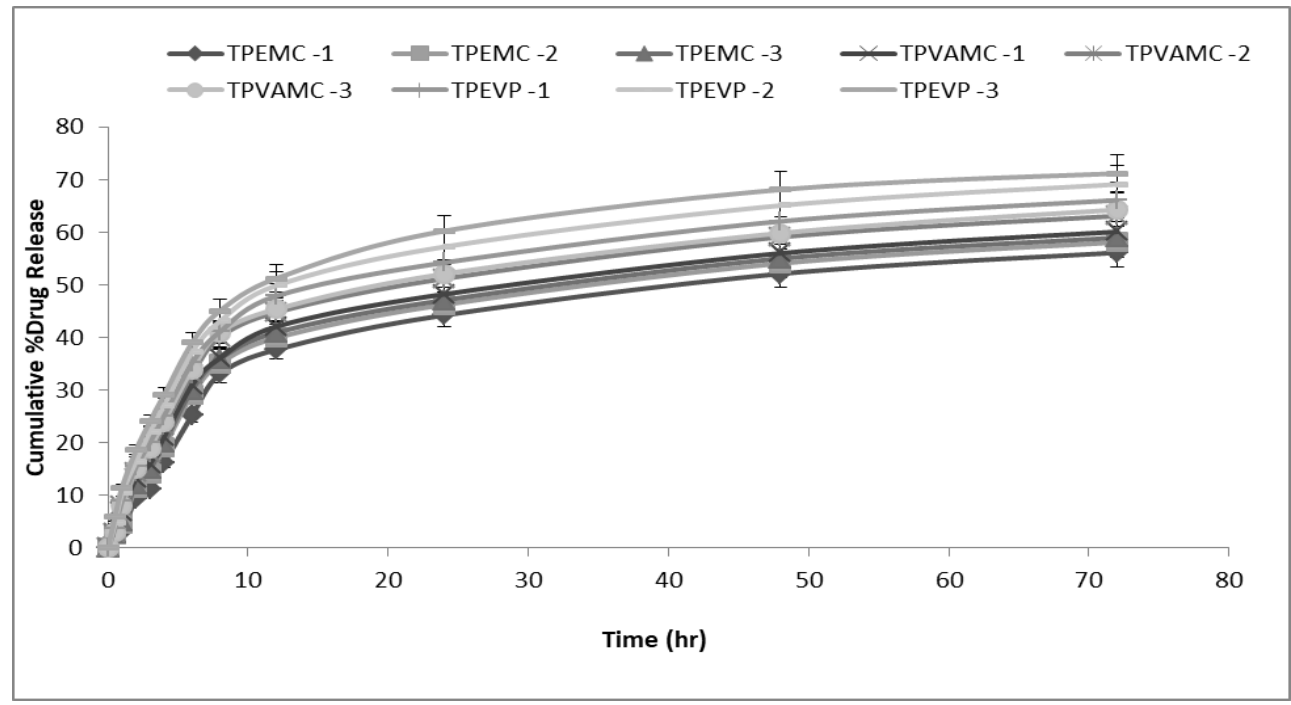

Figure 7 Comparative Drug Release Curve of Ex vivo diffusion study of patches

Drug release of final selected optimized batch (TPVAMC-1) was subjected to different kinetic models to study the mechanism of drug release from the patch and through the skin. Regression coefficient also suggested that drug release from the patch follow zero order and from the patch drug was release continuously in a controlled manner up to 72 hours (Table 3). The following batch has shown drug release for 24 hours to the extent of $48.24 \%$. The In vitro drug release plot has shown that the drug release followed zero order kinetics which was evidenced from the regression value of the above mentioned plot. The correlation coefficient (R2) of Higuchi's model was found to be 0.993 that indicate diffusion occurred (Table 4).

Ex vivo study was carried out in rat skin, formulation Batch TPVAMC (HPMC: PVA) showed drug diffusion, for 24 hours up to the extent of $60.12 \%$. To ensure the correlation between the In vitro and In vivo release pattern analysis was carried out. They are well correlated, so the release pattern is followed the predicted zero order kinetics in biological system also.

Skin irritation studies revealed that the batch TPVAMC (HPMC: PVA) has no erythema and oedema.

\section{Conclusion}

This study provide an valuable information regarding the transdermal drug delivery systems and its evaluation process details as a ready reference for the research scientist who are involved in TDDS. The foregoing shows that TDDS have great potentials, being able to use for both hydrophobic and hydrophilic active substance into promising deliverable drugs. To optimize this drug delivery system, greater understanding of the different mechanisms of biological interactions, and polymer are required. TDDS is a realistic practical application as the next generation of drug delivery system. And the batch TPVAMC (HPMC: PVA) has achieved the targets of present study such as extended release, prolonged zero order, reduced frequency of administration, and thus may improve the patient compliance.

\section{Compliance with ethical standards}

\section{Acknowledgments}

The authors thank the Ravishankar College of Pharmacy, People’s university, Bhopal, Madhya Pradesh India, for having made it possible to carry out this research work. 


\section{Disclosure of conflict of interest}

The authors report no conflicts of interest. The authors alone are responsible for the content and writing of this article.

\section{References}

[1] Harper, Mary Lea. Pharmacist's Drug Handbook. American Journal of Pharmaceutical Education. 2001; 65(3): 302.

[2] Keith, Alec D. Polymer matrix considerations for transdermal devices. Drug development and industrial pharmacy. 1983; 9(4): 605-625.

[3] Chien, Yie W. Development of transdermal drug delivery systems. Drug development and industrial pharmacy. 1987; 13(4-5): 589-651.

[4] Misra AN. Transdermal drug delivery. Controlled and novel drug delivery, 1st ed. New Delhi: CBS Publishers and Distributors. 1997; 100-29.

[5] Chien YW, GA Patani. Transdermal drug delivery devices: system design and composition. Encyclopedia of Pharmaceutical Technology. 1999; 18: 309-337.

[6] Butcher ME. Global experience with ondansetron and future potential. Oncology. 1993; 50(3): 191-197.

[7] McKenzie, Ray, Anthony Kovac, Thomas O'Connor, Deryck Duncalf, John Angel, Irwin Gratz, Eugene Tolpin, Charles McLeskey, Alan Joslyn. Comparison of ondansetron versus placebo to prevent postoperative nausea and vomiting in women undergoing ambulatory gynecologic surgery. Anesthesiology: The Journal of the American Society of Anesthesiologists. 1993; 78(1): 21-28.

[8] Scuderi, Phillip, Bernard Wetchler, Yung-Fong Sung, Melinda Mingus, Stuart DuPen, Louis Claybon, Pekka Talke, Jeffrey Apfelbaum, Said Sharifi-Azad, Melissa F. Williams. Treatment of postoperative nausea and vomiting after outpatient surgery with the 5-HT3 antagonist ondansetron. Anesthesiology: The Journal of the American Society of Anesthesiologists. 1993; 78(1): 15-20.

[9] Hesketh, Paul J, David R. Gandara. Serotonin antagonists: a new class of antiemetic agents. JNCI: Journal of the National Cancer Institute. 1991; 83(9): 613-620.

[10] Bozigian Haig P, J Frederick Pritchard, Ann E. Gooding, Gary E. Pakes. Ondansetron absorption in adults: effect of dosage form, food, and antacids. Journal of pharmaceutical sciences. 1994; 83(7): 1011-1013.

[11] Hsyu, Poe-Hirr, J Frederick Pritchard, Haig P Bozigian, Thomas L Lloyd, Rita H Griffin, Robert Shamburek, Gopal Krishna, William H. Barr. Comparison of the pharmacokinetics of an ondansetron solution $(8 \mathrm{mg})$ when administered intravenously, orally, to the colon, and to the rectum. Pharmaceutical research. 1994; 11(1): 156159.

[12] Hussain Anwar A, Adnan Dakkuri, Soichi Itoh. Nasal absorption of ondansetron in rats: an alternative route of drug delivery. Cancer chemotherapy and pharmacology. 2000; 45(5): 432-434.

[13] Gwak Hye Sun, Ik Sang Oh, In Koo Chun. In vitro percutaneous absorption of ondansetron hydrochloride from pressure-sensitive adhesive matrices through hairless mouse skin. Archives of pharmacal research. 2003; 26(8): 644-648.

[14] Chandra, Amrish, Pramod Kumar Sharma, Raghuveer Irchhiaya. Microemulsion-based hydrogel formulation for transdermal delivery of dexamethasone. Asian Journal of Pharmaceutics (AJP). 2014; 3(1).

[15] Kobayashi, Ichiro, Kyoko Hosaka, Hiroki Maruo, Yuji Saeki, Masashi Kamiyama, Chohachi Konno, Munekazu Gemba. Role of prostaglandin E2 and leukotriene B4 in skin reaction induced by transdermal application of propranolol. Biological and Pharmaceutical Bulletin. 2000; 23(2): 208-212.

[16] Slayden SM, L Crabbe, S Bae, HD Potter, Ricardo Azziz, CR Parker Jr. The effect of $17 \beta$-estradiol on adrenocortical sensitivity, responsiveness, and steroidogenesis in postmenopausal women. The Journal of Clinical Endocrinology \& Metabolism. 1998; 83(2): 519-524.

[17] Fischer, DuncanK, RichardK Simpson F. Ames Smith, and KennethL Mattox. "Efficacy of dexamethasone in benzodiazepine-resistant delirium tremens." The Lancet. 1988; 331(8598): 1340-1341.

[18] Heath, Donald, David Reid Williams. High-altitude medicine and pathology. Oxford University Press, USA. 1995. 
[19] Mantovani G, L Curreli, A Maccio, Elena Massa D Massa, C Mulas, G Succu, Paolo Contu. Prevention of nausea and vomiting $(\mathrm{N} \& \mathrm{~V})$ in cancer patients receiving high-dose cisplatin. Assessment of the potential antiemetic activity of transdermal fentanyl (TTS-F) compared to standard antiemetic treatment in acute and delayed N\&V: first clinical report." Anticancer research. 1999; 19(4C): 3495-3502.

[20] Nagashima M, K Wauke, D Hirano, S Ishigami, H Aono, M Takai, M Sasano, S Yoshino. Effects of combinations of anti-rheumatic drugs on the production of vascular endothelial growth factor and basic fibroblast growth factor in cultured synoviocytes and patients with rheumatoid arthritis. Rheumatology. 2000; 39(11): 1255-1262.

[21] Tsuei S Edmund, R George Moore, John J Ashley, William G McBride. Disposition of synthetic glucocorticoids I. Pharmacokinetics of dexamethasone in healthy adults." Journal of pharmacokinetics and biopharmaceutics. 1979; 7(3): 249-264.

[22] Arora Priyanka, Biswajit Mukherjee. Design, development, physicochemical, and In vitro and In vivo evaluation of transdermal patches containing diclofenac diethylammonium salt." Journal of pharmaceutical sciences. 2002; 91(9): 2076-2089.

[23] Ramkanth S, Alagusundaram M, Chetty M, Gnanprakash K. International journal of pharma research. 2009; 8891.

[24] Amnuaikit, Chomchan, Itsue Ikeuchi, Ken-ichi Ogawara, Kazutaka Higaki, Toshikiro Kimura. Skin permeation of propranolol from polymeric film containing terpene enhancers for transdermal use. International journal of pharmaceutics. 2005; 289(1-2): 167-178.

[25] Gupta R, M Bajpai, A Bhattacharya. Formulation and In vitro evaluation of transdermal drug delivery system of tizanidine hydrochloride." Indian Journal of Pharmaceutical Sciences. 2008; 7(4).

[26] Kusum Devi V, S Saisivam, GR Maria, PU Deepti. Design and evaluation of matrix diffusion controlled transdermal patches of verapamil hydrochloride. Drug development and industrial pharmacy. 2003; 29(5): 495-503.

[27] Hiremath, Shobha Rani R. Cytotoxicity, anti-tumor activity, cumulative skin irritation and sensitization study of 5-fluorouracil from a transdermal patch for dalton's lymphoma ascites cells. Journal of health science 53, no. 3 (2007): 275-281.Shaila L, Pandey S, Udupa N. Indian J. Pharm. Sci. 2006; 68(2): 179-184.

[28] Lewis, Shaila, N. Udupa. Design and evaluation of matrix type and membrane controlled transdermal delivery systems of nicotine suitable for use in smoking cessation. Indian journal of pharmaceutical sciences. 2006; 68(2).

[29] Arijit D, G Sibaji, KD Biplab, D Sudip. A novel technique for treating the type ll diabetes by transdermal patches prepared by using multiple polymer complexes. Int J Pharma Res Dev. 2010; 9: 195-204.

[30] Deshmane, Subhash V, Madhuri A Channawar, Anil V Chandewar, Unmesh M Joshi, Kailash R Biyani. Chitosan based sustained release mucoadhesive buccal patches containing verapamil HCl. Int. J. Pharm. Pharm. Sci. 2009; 1(1): 216-229.

[31] Garala, Kevin C, Anil J Shinde, Pratik H. Shah. Formulation and in-vitro characterization of monolithic matrix transdermal systems using HPMC/Eudragit S 100 polymer blends." Int J Pharm Pharm Sci. 2009; 1(1): 108-20.

[32] Patel Hemangi J, Jitendra S Patel, BG Desai, Keyur D Patel. Design and evaluation of amlodipine besilate transdermal patches containing film former. Int J Pharma Res Dev. 2009; 7(1).

[33] Thenge RR, Mahajan KG, Sawarkar HS, Adhao VS, Gangane PS. Formulation and Evaluation Of Transdermal Drug Delivery System For Lercanidipine Hydrochloride Int J. PharmTech Res. Jan-Mar 2010; 2(1): 253-258.

[34] Ubaidulla U, Reddy MV, Rukmani K, Ahmad FJ, Khar RK. AAPS pharma. Sci. Tech. 2007; 8(1): $212-216$.

[35] GT Burger, L Cheryl Miller. in: A. Wallace Hayes (Ed.), Principles and Methods of Technology, Raven Press, New York. 1989; 521- 570.

[36] Sarpotdar Pramod P, James L Gaskill, Robert P. Giannini. Effect of polyethlene glycol 400 on the penetration of drugs through human cadaver skin in vitro. Journal of pharmaceutical sciences. 1986; 75(1): 26-28.

[37] Gupta Ritu, Biswajit Mukherjee. Development and in vitro evaluation of diltiazem hydrochloride transdermal patches based on povidone-ethylcellulose matrices." Drug development and industrial pharmacy. 2003; 29(1): 1-7. 